Article

\title{
Fabrication of Magnetic Nanofibers by Needleless Electrospinning from a Self-Assembling Polymer Ferrofluid Cone Array
}

\author{
Weilong Huang ${ }^{1, \dagger}$, Bin Liu ${ }^{1, \dagger}{ }^{+}$Zhipeng Chen ${ }^{1}$, Hongjian Wang ${ }^{1}$, Lei Ren ${ }^{1}$, Jiaming Jiao ${ }^{1}$, \\ Lin Zhuang ${ }^{2}$, Jie Luo ${ }^{1}$ and Lelun Jiang ${ }^{1, *}$ \\ 1 School of Engineering, Guangdong Provincial Key Laboratory of Sensor Technology and Biomedical \\ Instrument, Sun Yat-Sen University, Guangzhou 510006, China; weilong_huang@foxmail.com (W.H.); \\ liub78@mail.sysu.edu.cn (B.L.); asm0844@163.com (Z.C.); Wanghjsysu@foxmail.com (H.W.); \\ rlei@mail2.sysu.edu.cn (L.R.); jiaojm@outlook.com (J.J.); jluo_bme@foxmail.com (J.L.) \\ 2 School of Physics, Sun Yat-Sen University, Guangzhou 510275, China; stszhl@mail.sysu.edu.cn \\ * Correspondence: jianglel@mail.sysu.edu.cn; Tel.: +86-20-39332153 \\ + These authors contributed equally to this work.
}

Received: 20 August 2017; Accepted: 13 September 2017; Published: 17 September 2017

\begin{abstract}
Magnetic nanofiber has been widely applied in biomedical fields due to its distinctive size, morphology, and properties. We proposed a novel needleless electrospinning method to prepare magnetic nanofibers from the self-assembling "Taylor cones" of poly(vinyl pyrrolidone) (PVP)/ $\mathrm{Fe}_{3} \mathrm{O}_{4}$ ferrofluid (PFF) under the coincident magnetic and electric fields. The results demonstrated that a static PFF Rosensweig instability with a conical protrusion could be obtained under the magnetic field. The tip of the protrusion emitted an electrospinning jet under the coincident magnetic and electric fields. The needleless electrospinning showed a similar process phenomenon in comparison with conventional electrospinning. The prepared nanofibers were composed of $\mathrm{Fe}_{3} \mathrm{O}_{4}$ particles and PVP polymer. The $\mathrm{Fe}_{3} \mathrm{O}_{4}$ particles aggregated inside and on the surface of the nanofibers. The nanofibers prepared by needleless electrospinning exhibited similar morphology compared with the conventionally electrospun nanofibers. The nanofibers also exhibited good ferromagnetic and magnetic field responsive properties.
\end{abstract}

Keywords: ferrofluid; self-assembling; needleless electrospinning; magnetic nanofibers

\section{Introduction}

Polymer magnetic composites are an exciting new class of multifunctional materials, where magnetic particles are incorporated into solid polymer matrices [1]. Polymer magnetic nanofiber is one of the most important one-dimensional (1D) magnetic materials due to its distinctive size, morphology, and unique magnetic properties [1]. The magnetic nanofibers are sensitive to change in external magnetic or electric field and can be applied in various fields, such as hyperthermia therapy [2], oil/water separation [3], targeting drug delivery [4], tissue engineering [5], microwave absorption [6], electronic and photoelectronic devices [7], and electromagnetic interference shielding [8], and so on. Therefore, magnetic nanofiber is worth synthesizing due to its broad applications.

Many synthetic approaches have been explored to prepare 1D magnetic nanostructures, including template-assisted growth [9], self-assembly [10], hydrothermal or solvothermal synthesis [11], nanolithography [12], metallization of DNA [13], electrospinning [14], and so on. Electrospinning has been demonstrated to be a versatile and feasible method to fabricate multifunctional composite nanofibers through incorporating various functionalities into the polymer solution with different nanofillers [15]. In conventional electrospinning, a high voltage is applied to a droplet of polymer 
solution to form the "Taylor cone". As the applied electric field is sufficiently high, the electrostatic force can overcome the surface tension of the polymer solution and exhaust a charged jet from the tip of the "Taylor cone". The charged jet then undergoes a stretching and whipping process, finally depositing on the counter-electrode in the formation of continuous nanofibers [16]. At present, the droplet is typically suspended at the edge of a needle attached to a vessel filled with polymer solution. A single jet is issued from a single needle, so the output of nanofibers is limited. Therefore, multi-needle electrospinning is employed to achieve a high production rate [17]. Multi-needle electrospinning is technologically inconvenient due to its complexity and high probability of clogging [18]. Needleless electrospinning methods can well solve the mass production and needle clogging problems [19]. Researchers have reported various needleless electrospinning techniques, such as porous spinnerets [20], wire spinnerets [21,22], rotary cylinder/cone/disk/convex slot spinnerets [23-26], bubble spinnerets [27], tip electrospinning of the liquid surface [28], and so on. Most of the needleless electrospinning techniques require extra power, such as the rotation of a roller driven by a motor, to form the "Taylor cones" for the electrospinning. The magnetic field can be used to form the "Taylor cones" of a ferrofluid. The Rosensweig instability of a magnetized ferrofluid has an electric analogue in the "Taylor cone" instability of an electrified fluid [29]. Yarin et al. [30] reported a magnetic-field-assisted needleless electrospinning method, which used a magnetic field to induce the formation of spikes on the solution surface and then initiated an electrospinning process. It is a two-layer system and an immiscible electrospinning solution is necessary to electrospin the nanofibers, which limits its further application. Magnetic nanofibers fabricated by this method have not been reported.

In this study, we propose a novel fabrication method of needleless electrospinning of the magnetic nanofibers from the self-assembling "Taylor cones" of a ferrofluid under simultaneous magnetic and electric fields. The "Taylor cones" of the ferrofluid were directly self-assembled under the permanent magnets without any extra power. The needleless electrospinning setup is extremely simple and cost-effective. The multiple parallel electromagnetostatic jets can be realized through the application of simultaneous magnetic and electric fields to the electrically-conducting ferrofluid with no needles [31]. Multiple parallel jets of a ferrofluid, directly used to electrospin the magnetic nanofibers, have not been investigated yet. Furthermore, the throughput of magnetic nanofibers can be easily controlled through tuning the number of "Taylor cones". In the next work, we will prepare a PVP $/ \mathrm{Fe}_{3} \mathrm{O}_{4}$ ferrofluid (short for PFF) for the needleless electrospinning of the nanofibers. The Rosensweig instability of ferrofluid and needleless electrospinning process under the simultaneous magnetic and electric fields also will be observed. The morphology and magnetic properties of $\mathrm{PVP} / \mathrm{Fe}_{3} \mathrm{O}_{4}$ nanofibers will be analyzed. We hope the magnetic nanofibers prepared in this work will be applied in biomedical fields, such as hyperthermia therapy and tissue engineering.

\section{Results and Discussion}

\subsection{Static Self-Assembling of PFF Droplet under Coincident Electric and Magnetic Fields}

The interaction between the adjacent droplets can be ignored due to their size and distribution [32], so we take one droplet as the research object. Figure $1 \mathrm{a}-\mathrm{c}$ present the formation behavior of a $2 \mu \mathrm{L}$ PFF droplet through the application of magnetic and electric fields. Both the 40-mm-diameter grade-N40 large permanent magnet and the 1.1-mm-thickness, 1.9-mm-diameter grade-N40 small permanent magnets were employed to generate an external magnetic field. The applied external magnetic field intensity was $35 \mathrm{mT}$ and the electric voltage was $5 \mathrm{kV}$. The PFF droplet lies quiescently and spreads out on the top surface of polydimethylsiloxane (PDMS) in the absence of applied fields, as shown in Figure 1a. Its contact angle is about $39^{\circ}$, which indicates the PFF wettability on the surface of PDMS, though PDMS has a relatively low surface tension [33]. The spreading droplet is drawn into an identical pointed cone geometry when the magnetic field is applied on the PFF droplet, as shown in Figure $1 b$, which is the Rosensweig instability of the PFF droplet by the static self-assembling under 
the magnetic field. The identical pointed geometry is slightly stretched in the normal direction of the droplet surface as the electric field (below the order of $108 \mathrm{~V} / \mathrm{m}$ ) is applied, as shown in Figure 1c. The same volume pure PVP droplet was employed to repeat the above experiment. The PVP droplet always spreads out on the surface of the PDMS block and its geometry varies little with or without application of magnetic and electric fields, as shown in Figure $1 \mathrm{~d}-\mathrm{f}$. The contact angle of the PVP droplet is also about $39^{\circ}$. This indicates that the magnetic and electric fields have little influence on the pure PVP droplet in comparison with the PFF droplet.
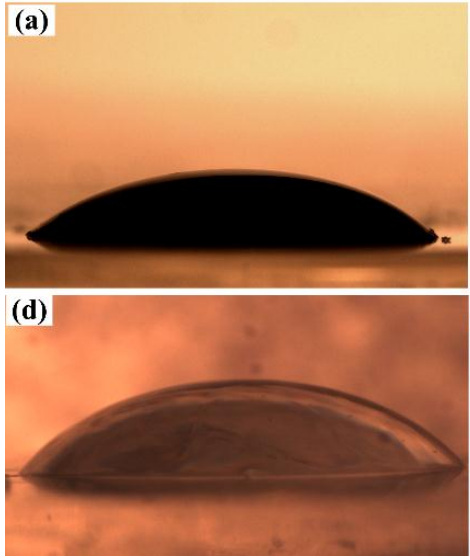
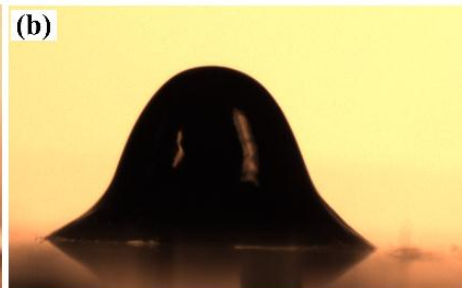

(e)

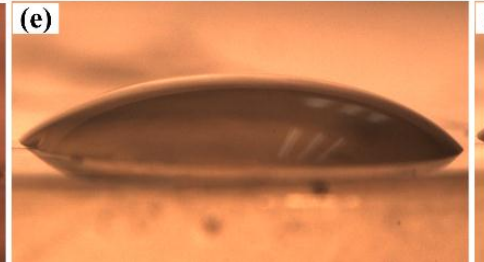

(c)

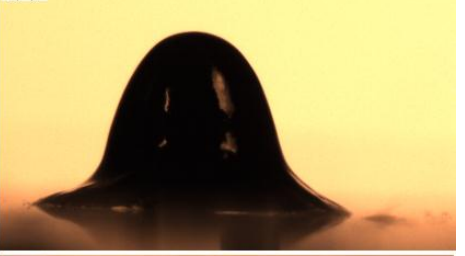

(f)

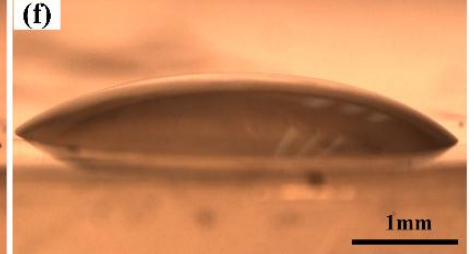

Figure 1. $\mathrm{PVP} / \mathrm{Fe}_{3} \mathrm{O}_{4}$ ferrofluid (PFF) droplet morphology (a) in air, (b) under the magnetic field, and (c) under the coincident magnetic and electric fields. Pure PVP droplet morphology (d) in air, (e) under the magnetic field, and (f) under the coincident magnetic and electric fields. The applied external magnetic field and electric voltage were about $35 \mathrm{mT}$ and $5 \mathrm{kV}$, respectively. All the subfigures share the same scale.

Self-assembly is a process in which interacting bodies are autonomously driven into ordered structures by free-energy gradients [32]. The static self-assembling behavior of PFF a droplet can be analyzed on the potential energy of applied fields and their interaction with the fluid volume. As the net energy of the system reaches a minimum value, the equilibrium shape of fluid appears [32]. In the absence of applied field, the PFF droplet lies on the PDMS due to the simultaneous minimization of the gravitational and surface tension potential energy, as shown in Figure 1a. As a magnetic field is applied to the PFF droplet, a curved droplet surface (Rosensweig surface) is stretched and protrudes in the vertical direction [34], as shown in Figure 1b. This increases the gravitational and surface tension potential energy over a flat droplet, but simultaneously decreases the magnetic potential energy due to the PFF droplet features aligned with the magnetic field [29]. The magnetic potential energy increases with the extension of the PFF droplet along the magnetic field where the magnetic field gradient is great, as shown in Figure 7b. The iron pillar serving as an electrode can generate a high magnetic field gradient at its top ends, resulting in the formation the cone array of PFF. A greater magnetic field gradient can induce and transfer a larger magnetic force on the PFF droplet, sharpening the PFF droplet along the magnetic field line. A new balance is reached as the sum of gravity, surface tension, and magnetic force is zero, or the net energy of the system is minimized. The magnetostatic Rosensweig surface created in the PFF serves the same role as the electrified capillary in conventional electrospinning. With the application of coincident magnetic and electric fields on a PFF droplet, the curved PFF droplet surface is stretched and grows slightly taller by the electrostatic force, as shown in Figure 1c. The applied electric voltage here is, relatively, too low to form the "Taylor Cone". The magnetic force acts together with the electrostatic traction to deform the meniscus. If the electric voltage is increased further, the meniscus can be further stressed by the electric field and results in the eventual spray from the cone tip [29]. 


\subsection{Needleless Electrospinning Process}

The needleless electrospinning process of one PFF droplet was captured by a high-speed camera at $2000 \mathrm{fps}$ and analyzed frame by frame, as shown in Figure 2. The curved peak is self-assembled under the magnetic field, as shown in Figure 2a, which is identical with that in Figure 1b. The peak is electrified and large quantities of electric charge are accumulated at the apex as the high voltage is applied. The peak becomes sharper and a "Taylor cone" forms due to the electrostatic force, as shown in Figure 2b. Once the critical threshold voltage is reached, the curved peak of the droplet abruptly becomes a sharp point, triggering the onset of jet emission from the "Taylor cone", as shown in Figure 2c. Electrospinning occurs as the electrostatic surface traction exceeds the PFF droplet surface tension. The jet is stretched, elongated and whipped by electrostatic repulsion in the electric field, as shown in Figure $2 \mathrm{~d}-\mathrm{f}$. The jet dries with the solvent evaporation in flight, becoming finer and finer, and ultimately deposits the magnetic nanofibers on the grounded collector. The jet tapers off as the applied high voltage on $\mathrm{PVP} / \mathrm{Fe}_{3} \mathrm{O}_{4}$ ferrofluid is turned down, resulting in diminution of needless electrospinning, as shown in Figure $2 \mathrm{~g}, \mathrm{~h}$. This process is similar with the conventional electrospinning process. Conventional electrospinning is an exclusively electrostatic process, while the needleless electrospinning is a magnetoelectrostatic process. The multiple parallel cone array of PFF droplets can be simultaneously self-assembled to electrospin nanofibers under the coincident electric and magnetic fields.

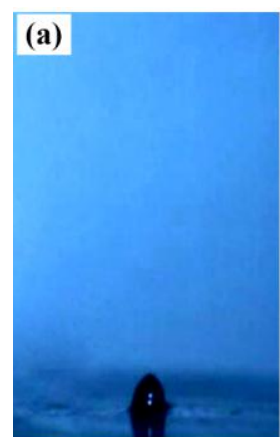

(e)

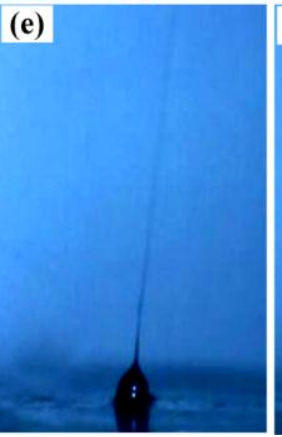

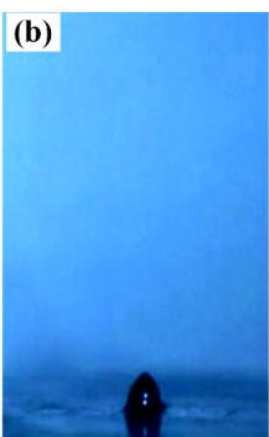

(f)

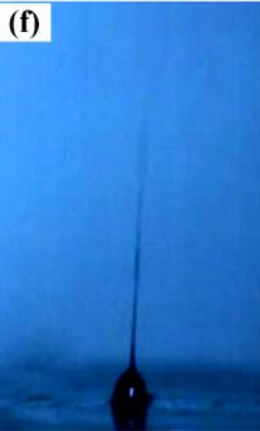

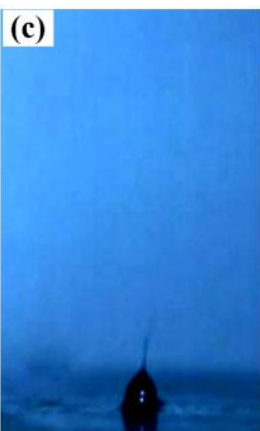

(g)

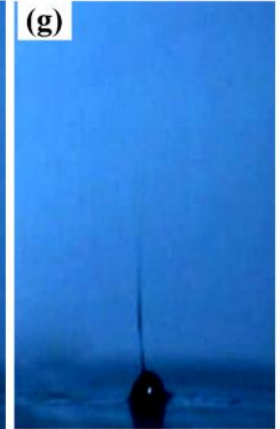

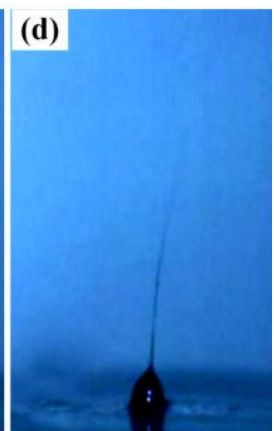

(h)

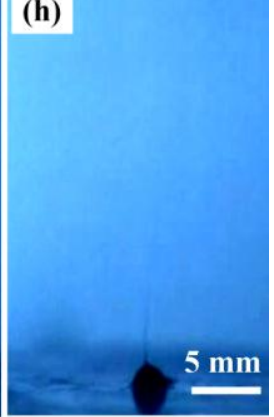

Figure 2. Needleless electrospinning process captured by a high-speed camera. (a) Self-assembling of ferrofluid, (b) formation of Taylor Cone, (c) onset of jet emission, (d-f) electrospinning process, $(\mathbf{g}, \mathbf{h})$ diminution of needless electrospinning. All the subfigures share the same scale.

\subsection{Morphology of Nanofibers}

The SEM images of PVP $/ \mathrm{Fe}_{3} \mathrm{O}_{4}$ nanofibers are shown in Figure $3(\mathrm{a} 1, \mathrm{~b} 1, \mathrm{c} 1)$. As observed, the collected nanofibers all display a random orientation due to the bending instability associated with the spinning jet [35]. The morphology of nanofibers prepared by the needleless electrospinning is similar to those by the conventional electrospinning. The surfaces of nanofibers are all rough due to the $\mathrm{Fe}_{3} \mathrm{O}_{4}$ particles wrapped on their surface. The inner microstructures of the nanofibers were further investigated by TEM, as shown in Figure 3(a2,b2,c2). As observed, the $\mathrm{Fe}_{3} \mathrm{O}_{4}$ particles are dispersed 
both in and on the surface of the nanofibers. Most particles are wrapped in the nanofibers, while some sections of nanofibers contain pure PVP without any $\mathrm{Fe}_{3} \mathrm{O}_{4}$ particles inside. The aggregation of the $\mathrm{Fe}_{3} \mathrm{O}_{4}$ nanoparticles in the nanofibers may be attributed to the following possible reasons: (1) the $\mathrm{Fe}_{3} \mathrm{O}_{4}$ nanoparticles are distributed uniformly in PFF due to the different densities between the PVP and nanoparticles. (2) The $\mathrm{Fe}_{3} \mathrm{O}_{4}$ nanoparticles tend to agglomerate each other to reduce its own energy in the PFF due to their high surface-to-volume ratio by electrostatic attraction. (3) The external magnetic field during the needleless electrospinning may further exacerbate the aggregation of $\mathrm{Fe}_{3} \mathrm{O}_{4}$ particles in the PFF due to the magnetic attraction. The cumulative frequency distribution of the electrospun nanofiber diameters is shown in Figure 3(a3,b3,c3). The average diameters of nanofibers are $557 \pm 258 \mathrm{~nm}, 645 \pm 340 \mathrm{~nm}$, and $464 \pm 149 \mathrm{~nm}$ for the $\mathrm{Fe}_{3} \mathrm{O}_{4}$ particle concentrations of $0.2 \mathrm{~g} / \mathrm{mL}$ needleless, $0.25 \mathrm{~g} / \mathrm{mL}$ needleless, and $0.2 \mathrm{~g} / \mathrm{mL}$ needle electrospinning, respectively. The average diameter of nanofibers by needleless electrospinning increases with the $\mathrm{Fe}_{3} \mathrm{O}_{4}$ particle concentration of PFF. It may be explained by the viscosity of PFF increasing with the $\mathrm{Fe}_{3} \mathrm{O}_{4}$ particle concentration of PFF. The standard deviation of needleless electrospinning nanofiber diameter is larger in comparison with conventional electrospinning. It may indicate that the needle electrospinning process is more unstable. Therefore, the needleless electrospinning can prepare magnetic nanofibers with multiple parallel jets under the coincident electric and magnetic fields.
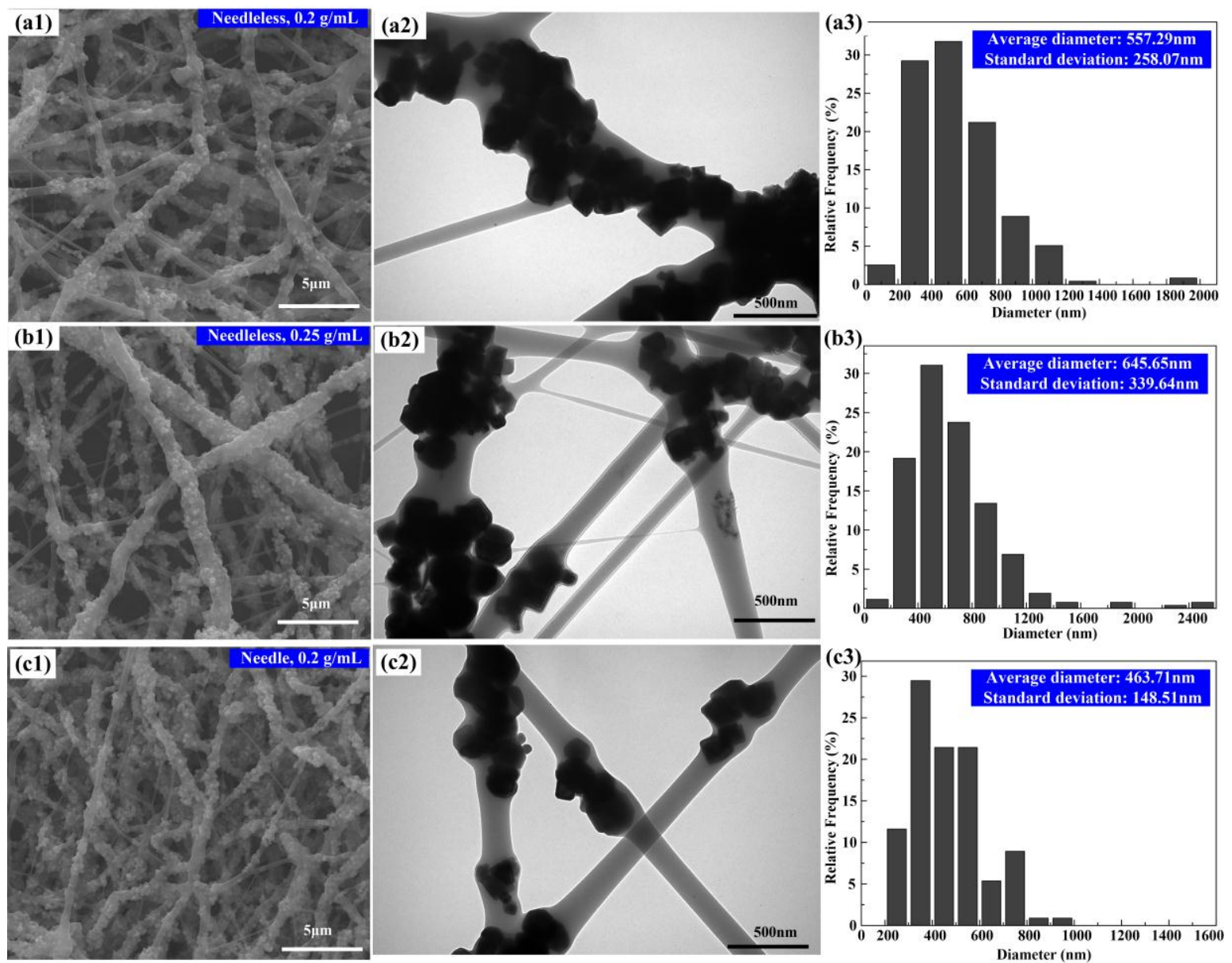

Figure 3. SEM images, TEM images, and the respective diameter histogram, of $\mathrm{PVP} / \mathrm{Fe}_{3} \mathrm{O}_{4}$ nanofibers. Nanofibers fabricated by multiple needleless electrospinning with $\mathrm{Fe}_{3} \mathrm{O}_{4}$ concentration of (a) $0.2 \mathrm{~g} / \mathrm{mL}$ and (b) $0.25 \mathrm{~g} / \mathrm{mL}$. (c) Nanofibers fabricated by conventional electrospinning with a $\mathrm{Fe}_{3} \mathrm{O}_{4}$ concentration of $0.2 \mathrm{~g} / \mathrm{mL}$. 


\subsection{TGA Analysis}

The thermal degradations of PVP $/ \mathrm{Fe}_{3} \mathrm{O}_{4}$ and neat PVP nanofibers were evaluated by measuring weight loss vs. temperature of the nanofibers. TGA curves of $\mathrm{PVP} / \mathrm{Fe}_{3} \mathrm{O}_{4}$ and neat PVP nanofibers are shown in Figure 4. A minor weight loss at approximately $100{ }^{\circ} \mathrm{C}$ is showed in the TGA curves. It is related to the loss of moisture absorbed by the nanofibers and the solvent trapped in the fibers [36]. A major weight loss is observed from $410{ }^{\circ} \mathrm{C}$ to $480{ }^{\circ} \mathrm{C}$ in the TGA curves due to the combustion of organic PVP matrix. No further weight loss is observed up to $700{ }^{\circ} \mathrm{C}$, which indicates that the polymer has been completely removed. The substance left is $\mathrm{Fe}_{3} \mathrm{O}_{4}$ particles. The degradation temperature of $\mathrm{Fe}_{3} \mathrm{O}_{4}$ is beyond $1000{ }^{\circ} \mathrm{C}$. The weights of $\mathrm{Fe}_{3} \mathrm{O}_{4}$ particles left are $75 \%$ and $77 \%$ for the $\mathrm{Fe}_{3} \mathrm{O}_{4}$ concentrations of PFF at $0.2 \mathrm{~g} / \mathrm{mL}$ and $0.25 \mathrm{~g} / \mathrm{mL}$, respectively. The concentration of PVP/ethanol solution is $7 \mathrm{wt} \%$. The theoretically weights of $\mathrm{Fe}_{3} \mathrm{O}_{4}$ in the nanofibers are $74 \%$ at $0.2 \mathrm{~g} / \mathrm{mL}$ and $78 \%$ at $0.25 \mathrm{~g} / \mathrm{mL}$. Therefore, the experimental TGA values agree with the theoretical ones.

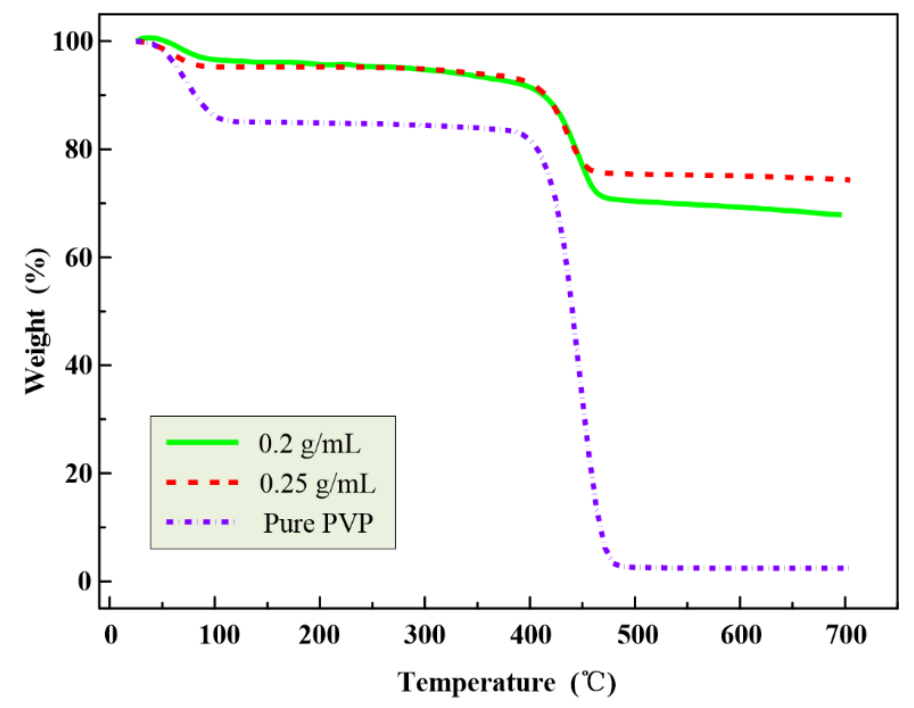

Figure 4. TGA curves of $\mathrm{PVP} / \mathrm{Fe}_{3} \mathrm{O}_{4}$ and pure PVP nanofibers.

\subsection{Fourier Transform Infrared Spectroscopy (FT-IR) Analysis}

Figure 5 shows the FT-IR spectra of $\mathrm{PVP} / \mathrm{Fe}_{3} \mathrm{O}_{4}$ nanofibers prepared by needleless electrospinning and neat PVP nanofibers by conventional electrospinning. The main absorption peaks of neat PVP shown in Figure $5 \mathrm{a}$ at $3531 \mathrm{~cm}^{-1}, 2952 \mathrm{~cm}^{-1}, 1429 \mathrm{~cm}^{-1}, 1670 \mathrm{~cm}^{-1}$, and $1282 \mathrm{~cm}^{-1}$ are assigned to the $\mathrm{O}-\mathrm{H}$ stretching, $\mathrm{C}-\mathrm{H}$ stretching, $\mathrm{C}-\mathrm{H}$ bending, $\mathrm{C}=\mathrm{O}$ stretching vibration, and the tertiary amine and $\mathrm{C}-\mathrm{N}$ vibration, respectively. These absorption peaks observed confirm the existence of PVP groups which are also presented in the FT-IR spectra of PVP $/ \mathrm{Fe}_{3} \mathrm{O}_{4}$ nanofibers, as shown in Figure $5 \mathrm{~b}$,c. However, an extra band of the metal oxide $\mathrm{Fe}-\mathrm{O}$ at $570 \mathrm{~cm}^{-1}$ is observed in the FT-IR spectra of $\mathrm{PVP} / \mathrm{Fe}_{3} \mathrm{O}_{4}$ nanofibers. The absorption peak of $\mathrm{Fe}-\mathrm{O}$ was at around $551 \mathrm{~cm}^{-1}$, according to the previous research [37]. This slight shift of $\mathrm{Fe}-\mathrm{O}$ absorption peak may be attributed to the interaction between $\mathrm{Fe}_{3} \mathrm{O}_{4}$ nanoparticles and nanofibers [37]. The FT-IR spectrum of $\mathrm{PVP} / \mathrm{Fe}_{3} \mathrm{O}_{4}$ nanofibers at the $\mathrm{Fe}_{3} \mathrm{O}_{4}$ concentration of $0.25 \mathrm{~g} / \mathrm{mL}$ shows a similar profile with that of $\mathrm{PVP} / \mathrm{Fe}_{3} \mathrm{O}_{4}$ nanofibers at $0.2 \mathrm{~g} / \mathrm{mL}$. 


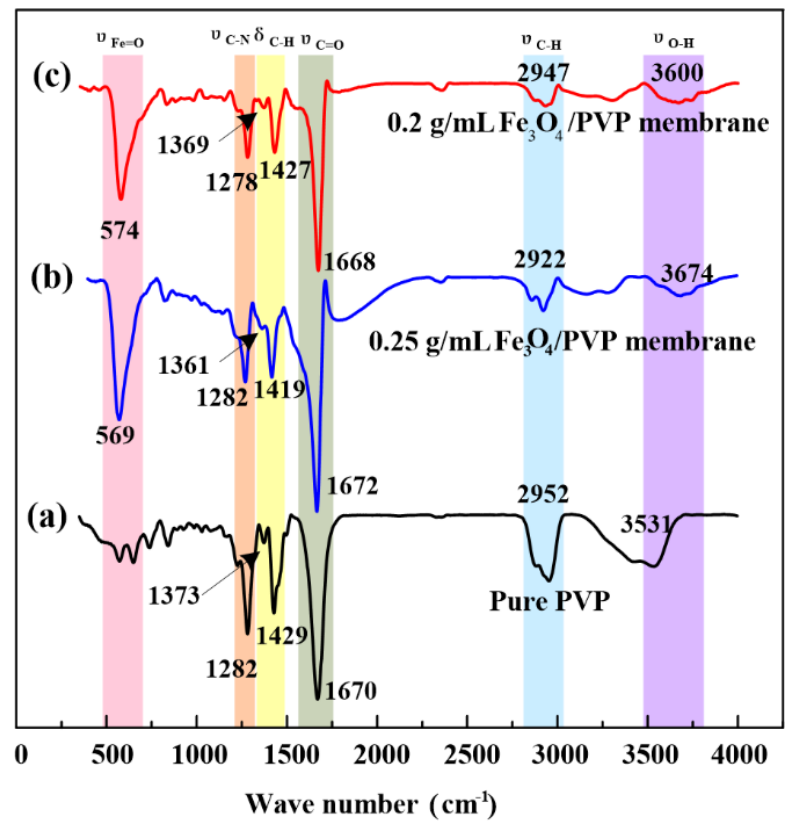

Figure 5. FT-IR spectra of (a) neat PVP nanofibers, (b) PVP $/ \mathrm{Fe}_{3} \mathrm{O}_{4}$ nanofibers at $0.25 \mathrm{~g} / \mathrm{mL} \mathrm{Fe}_{3} \mathrm{O}_{4}$ particle concentration, and (c) $\mathrm{PVP} / \mathrm{Fe}_{3} \mathrm{O}_{4}$ nanofibers at $0.2 \mathrm{~g} / \mathrm{mL} \mathrm{Fe}_{3} \mathrm{O}_{4}$ particle concentration.

\subsection{Magnetic Properties Analysis}

Magnetic hysteresis loops of PVP $/ \mathrm{Fe}_{3} \mathrm{O}_{4}$ membranes prepared by needleless electrospinning and $\mathrm{Fe}_{3} \mathrm{O}_{4}$ particles were obtained by VSM at room temperature, as shown in Figure 6a,b. Hysteresis loops misalign for both $\mathrm{Fe}_{3} \mathrm{O}_{4}$ particles and $\mathrm{PVP} / \mathrm{Fe}_{3} \mathrm{O}_{4}$ membranes, which means they are ferromagnetic. The specific saturation magnetization $\left(M_{s}\right)$ values for pure $\mathrm{Fe}_{3} \mathrm{O}_{4}$ particles, $0.25 \mathrm{~g} / \mathrm{mL}$ and $0.2 \mathrm{~g} / \mathrm{mL}$ $\mathrm{PVP} / \mathrm{Fe}_{3} \mathrm{O}_{4}$ membranes are $91 \mathrm{emu} / \mathrm{g}, 70 \mathrm{emu} / \mathrm{g}$, and $55 \mathrm{emu} / \mathrm{g}$, respectively. The decrease in saturation magnetization value of $\mathrm{Fe}_{3} \mathrm{O}_{4} / \mathrm{PVP}$ composite nanofibers in comparison with $\mathrm{Fe}_{3} \mathrm{O}_{4}$ nanoparticles can be explained as: firstly, the existence of nonmagnetic PVP components encapsulate $\mathrm{Fe}_{3} \mathrm{O}_{4}$ nanoparticles, which affects the magnetization expression of $\mathrm{Fe}_{3} \mathrm{O}_{4}$ nanoparticles; secondly, the wide size distribution of $\mathrm{Fe}_{3} \mathrm{O}_{4}$ nanoparticles in the nanofibers, as shown in Figure 3. The size, aggregation and uniformity of particles play a very important role in the magnetic properties [35]. The saturation magnetization of $0.25 \mathrm{~g} / \mathrm{mL} \mathrm{PVP} / \mathrm{Fe}_{3} \mathrm{O}_{4}$ membranes is larger than that of $0.2 \mathrm{~g} / \mathrm{mL}$ PVP $/ \mathrm{Fe}_{3} \mathrm{O}_{4}$ membranes. $M_{s}$ is proportional to the amount of $\mathrm{Fe}_{3} \mathrm{O}_{4}$ in the composite nanofibers [38]. The coercive forces of $\mathrm{Fe}_{3} \mathrm{O}_{4}$ nanoparticles and $\mathrm{Fe}_{3} \mathrm{O}_{4} / \mathrm{PVP}$ composite nanofibers are all $105 \mathrm{G}$ at room temperature as shown in Figure $6 \mathrm{~b}$. The remanence of pure $\mathrm{Fe}_{3} \mathrm{O}_{4}$ particles, $0.25 \mathrm{~g} / \mathrm{mL}$ and $0.2 \mathrm{~g} / \mathrm{mL} \mathrm{PVP} / \mathrm{Fe}_{3} \mathrm{O}_{4}$ membranes are $10 \mathrm{emu} / \mathrm{g}$ and $7 \mathrm{emu} / \mathrm{g}$, and $6 \mathrm{emu} / \mathrm{g}$, respectively. It indicates that ferromagnetic responses are expected at room temperature. A PVP $/ \mathrm{Fe}_{3} \mathrm{O}_{4}$ membrane at $\mathrm{Fe}_{3} \mathrm{O}_{4}$ concentration of $0.25 \mathrm{~g} / \mathrm{mL}$ was needleless electrospun, as shown in Figure 6c. One end of the membrane was fastened onto the surface of a table, while the other end was free to move. The magnetic field responsive behavior of this $\mathrm{PVP} / \mathrm{Fe}_{3} \mathrm{O}_{4}$ membrane with a N40 permanent magnet was observed in Figure $6 \mathrm{c}, \mathrm{d}$. As the magnet came closer to the membrane, a greater magnetic field gradient was induced to transfer larger magnetic force on membrane, causing the free end of the membrane to move towards the magnet. This demonstrated that the $\mathrm{PVP} / \mathrm{Fe}_{3} \mathrm{O}_{4}$ membrane had a good magnetic response property. 

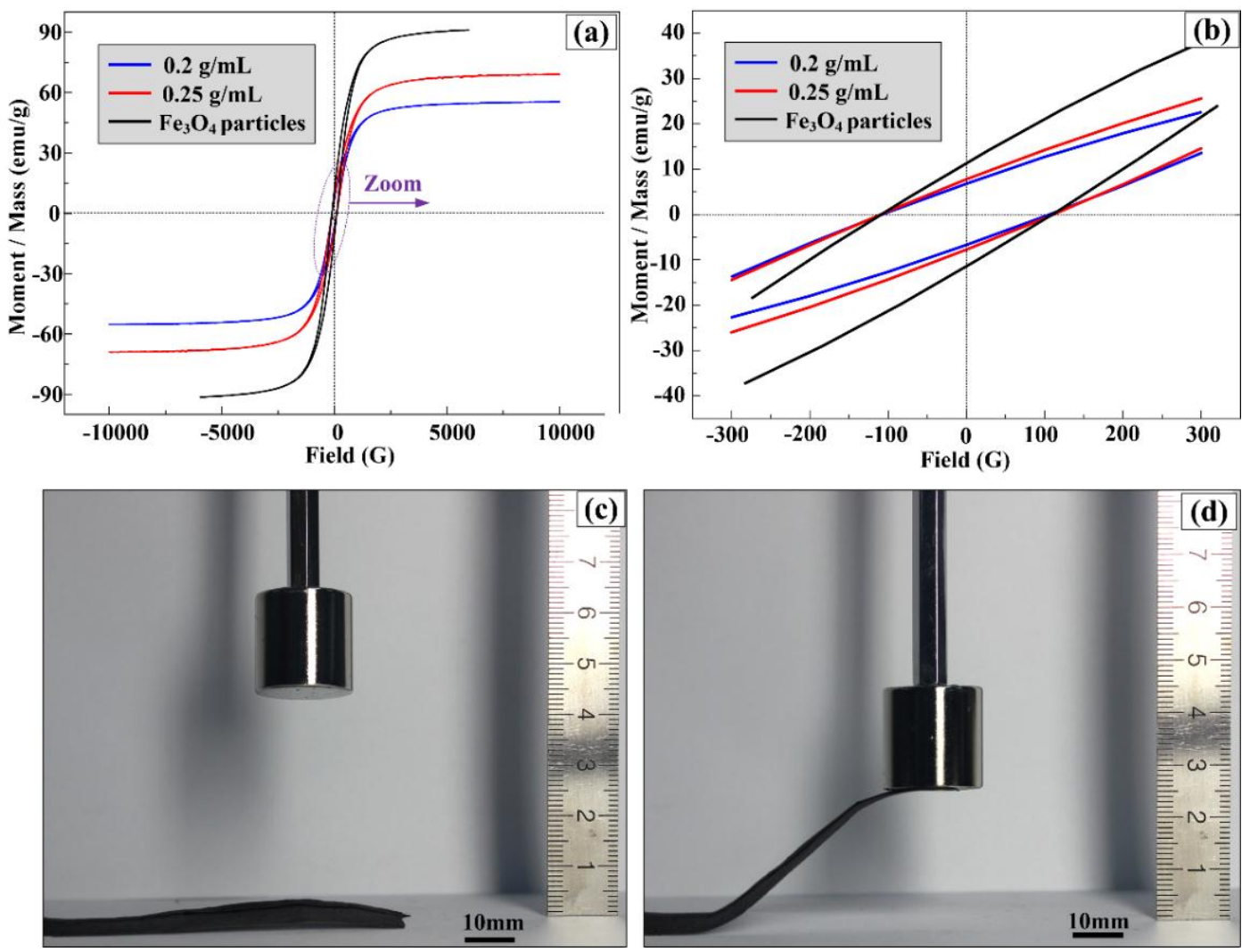

Figure 6. (a) Magnetic hysteresis loops of $\mathrm{Fe}_{3} \mathrm{O}_{4}$ particles and $\mathrm{PVP} / \mathrm{Fe}_{3} \mathrm{O}_{4}$ membranes, (b) detailed view of the magnetic hysteresis loops at the origin, and $(\mathbf{c}, \mathbf{d})$ the magnetic field responsive behavior of $\mathrm{PVP} / \mathrm{Fe}_{3} \mathrm{O}_{4}$ membrane.

\section{Materials and Methods}

\subsection{Preparation of $\mathrm{PVP} / \mathrm{Fe}_{3} \mathrm{O}_{4}$ Ferrofluid}

Poly(vinyl pyrrolidone) (PVP, $\left.\mathrm{M}_{\mathrm{w}}=1,300,000\right)$ was purchased from Aladdin Industrial Corporation, Shanghai, China. PVP was dissolved in the ethanol (99.5\%, Guangzhou Chemical Reagent Factory, Guangzhou, China) at a concentration of $7 \%$ under sufficiently stirring for about $12 \mathrm{~h}$ at room temperature. $\mathrm{Fe}_{3} \mathrm{O}_{4}$ nanoparticles (99.5\%; average diameter: $20 \mathrm{~nm}$; saturation magnetization: 400 Gauss; Aladdin Industrial Corporation, Shanghai, China) were purchased as ferrite magnetic particles. Magnetite $\left(\mathrm{Fe}_{3} \mathrm{O}_{4}\right)$ has been widely used in biomedical applications, such as magnetic resonance imaging (MRI), drug delivery, biosensors, magnetic separation, and medical diagnostics due to its innate biological compatibility [39]. The surface of the magnetic particles was modified by sodium oleate $(98 \%$, Shanghai Macklin Biochemical Co., Ltd., Shanghai, China).

$\mathrm{Fe}_{3} \mathrm{O}_{4}$ particles were dispersed in deionized water at $4 \%(w / v)$ by ultrasonic stirring at $70{ }^{\circ} \mathrm{C}$. Subsequently, the surfactant sodium oleate was slowly added into the $\mathrm{Fe}_{3} \mathrm{O}_{4}$ / water solution at a ratio of 1:4 $(w / v)$ and stirred for about $45 \mathrm{~min}$. The modified $\mathrm{Fe}_{3} \mathrm{O}_{4}$ particles were precipitated using a strong $\mathrm{NbFeB}$ magnet and washed by ethanol solution several times to remove excessive sodium oleate. The modified $\mathrm{Fe}_{3} \mathrm{O}_{4}$ particles with sodium oleate were dried. The concentration of PVP/ethanol solution $(7 \%)$ was prepared, because it was a proper concentration for the electrospinning of PVP nanofibers and good dispersion of $\mathrm{Fe}_{3} \mathrm{O}_{4}$ particles. The modified $\mathrm{Fe}_{3} \mathrm{O}_{4}$ particles were added to the $\mathrm{PVP} / \mathrm{ethanol}$ solution at the concentrations of $0.2 \mathrm{~g} / \mathrm{mL}$ and $0.25 \mathrm{~g} / \mathrm{mL}$ in this experiment. Then the solution was stirred and dispersed by vortex and ultrasound. A relatively homogeneous polymeric PFF was prepared. The PFF was served as a raw solution for electrospinning of magnetic nanofibers. 


\subsection{Design of Needleless Electrospinning Apparatus}

A needleless electrospinning apparatus for the preparation of magnetic nanofibers was self-developed, as shown in Figure 7a. The apparatus was composed of the magnetic field generator module and high electric field generator module. A 3-mm-height, 0.5-mm-diameter pure iron pillar was vertically and magnetically attracted by a 1.1-mm-thickness, 1.9-mm-diameter grade-N40 small permanent magnet. The small permanent magnets were connected with a copper strip. The pillars, small permanent magnets, and copper strip were totally embedded in a 30-mm-diameter solidified polydimethylsiloxane (PDMS) block. Only the top surface of the pillar end was exposed to air and directly contacted the PFF. The high electric field was generated by a high-voltage power supply (DW-P303-1ACF0, Tianjing Dongwen High Voltage Power Supply Plant, Tianjing, China) and directly applied on the PFF through the iron pillars. The collector was placed $10 \mathrm{~cm}$ away from the top surface of PDMS block and connected to the ground electrode of the high-voltage power supply.
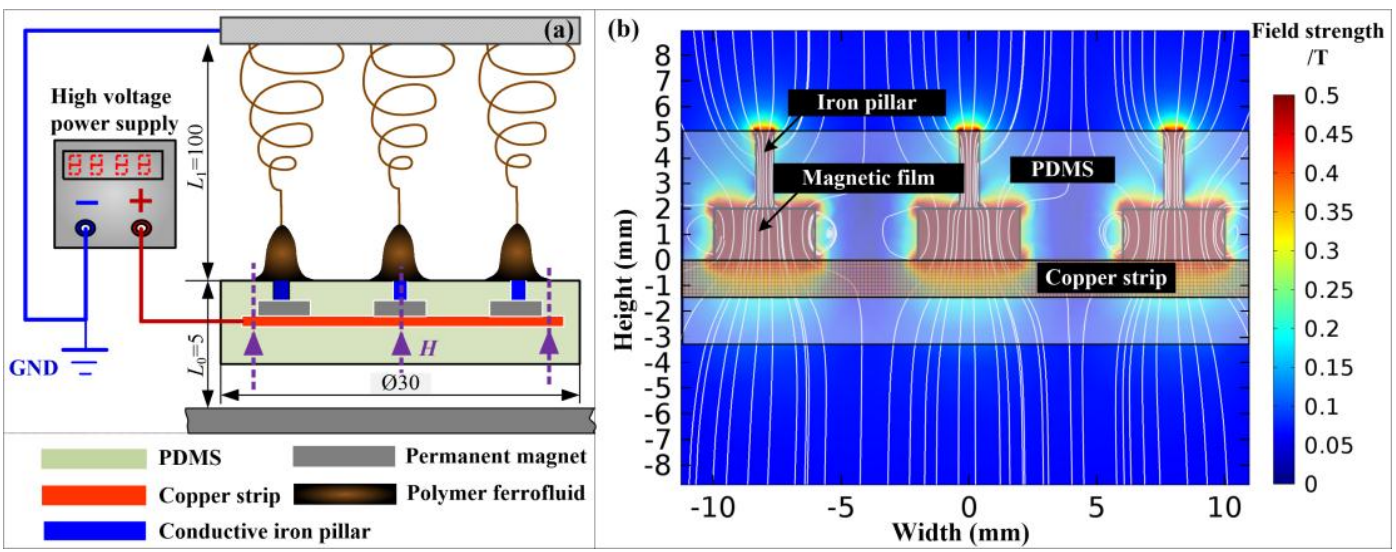

Figure 7. (a) Schematic image of needleless electrospinning apparatus, and (b) the magnetic field distribution of apparatus calculated by finite element analysis (FEA).

A 6-mm-thickness, 40-mm-diameter grade-N40 large permanent magnet was placed below the PDMS block with a distance of approximately $5 \mathrm{~mm}$. This arrangement created a magnetic field directed normally to the top surface of PDMS block with a uniform flux intensity $(H)$ of $75 \mathrm{mT}$. The pure iron pillar was further magnetized by the small permanent magnets. The residual flux intensity $\left(B_{r}\right)$ and relative magnetic permeability $\left(\mu_{r}\right)$ of small magnets were $1.24 \mathrm{~T}$ and 1.05 , respectively. The relative magnetic permeability of the iron pillar was 4000. The PFF was magnetized to form a cone droplet. The magnetic field distribution of the apparatus was numerically calculated with COMSOL Multiphysics 5.0 softwarefigure, as shown in Figure $7 \mathrm{~b}$. The simulation model was built based on the physical size of apparatus. The equivalent magnetic charge method was employed to calculate the distribution of the magnetic field.

\subsection{Fabrication of Magnetic Nanofibers}

The needleless electrospinning procedures for the preparation of magnetic nanofibers were as follows: (1) about $2 \mu \mathrm{L}$ PFF was poured on a PDMS block with a pipette at each top end of the pillar. (2) The PFF was self-assembled into a droplet cone under the magnetic field. (3) A high-voltage power supply was adjusted at $28 \mathrm{kV}$ and a high electric field was applied to the PFF cone-shape-droplets. The needleless electrospinning occurred and the nanofibers were collected. (4) This needleless electrospinning process was observed by a high-speed camera with a $10 \times$ lens (Fastec TS3-Model 100-S/L, Fastec Imaging Corporation, San Diego, CA, USA). (5) The nanofibers were vacuum dried for $24 \mathrm{~h}$ and stored in a vacuum-sealed desiccator to prevent the absorption of moisture. 
The conventional needle electrospinning of PFF was also employed to prepare magnetic nanofibers. The applied voltage was $12 \mathrm{kV}$, the tip-to-collector distance was $10 \mathrm{~cm}$ and the mass flow rate was $0.8 \mathrm{~mL} / \mathrm{h}$. Both the needleless and needle electrospinning were performed at room temperature $\left(25^{\circ} \mathrm{C}\right)$ under a relative humidity of $40-45 \%$.

\subsection{Characterization Methods}

The prepared magnetic nanofibers were characterized and analyzed by SEM, TEM, TGA, FT-IR, and VSM. The morphology of the resulting nanofibers was observed using a field emission scanning electron microscope (FESEM, JSM-6330F, JEOL Ltd., Tokyo, Japan). The internal morphology of composite nanofibers was studied using a transmission electron microscopy (TEM, Tecnai 10 Philips, Amsterdam, The Netherlands). The diameter of nanofibers was measured by Image-J image analysis software (National Institutes of Health, Bethesda, MD, USA) with about 100 randomly-selected nanofibers from each SEM image. Thermogravimetric analysis of nanofibers was carried out on a TGA instrument (TGA/SDTA85e, Mettler Toledo, Zurich, Switzerland) with a heating rate of $10^{\circ} \mathrm{C} / \mathrm{min}$ from $25^{\circ} \mathrm{C}$ to $700{ }^{\circ} \mathrm{C}$ under a nitrogen atmosphere of $50 \mathrm{~mL} / \mathrm{h}$. The functional groups of nanofibers were studied by FT-IR (TENSOR27 Bruker, Karlsruhe, Germany). The magnetization versus the applied magnetic field curves (M-H curves) of magnetic nanofibers and $\mathrm{Fe}_{3} \mathrm{O}_{4}$ particles were evaluated using a vibrating sample magnetometer (VSM, Lake Shore 7410, Westerville, OH, USA) at room temperature.

\section{Conclusions}

We presented a novel needleless electrospinning method for the preparation of magnetic nanofibers from the self-assembling ferrofluid cone array under simultaneous magnetic and electric fields. The PVP $/ \mathrm{Fe}_{3} \mathrm{O}_{4}$ ferrofluid was prepared for the needleless electrospinning. When the PFF droplet is subject to a magnetic field, the PFF shows a static Rosensweig instability with a conical protrusion on the free surface. When the surface is further stressed by an electric field, the tip of the protrusion emits an electrospinning jet. Both the electric and magnetic effects act in concert to draw the meniscus, ultimately causing the PFF jetting and electrospinning. The needleless electrospinning shows a similar process phenomenon in comparison with the conventional electrospinning. The needleless electrospinning jet becomes finer, and is finally deposited on the collector as the magnetic nanofibers. The nanofibers prepared by the needleless electrospinning show similar morphology in comparison with conventional electrospinning. The $\mathrm{Fe}_{3} \mathrm{O}_{4}$ particles distribute and aggregate both inside and on the surface of the nanofibers. The magnetic nanofibers consist of $\mathrm{Fe}_{3} \mathrm{O}_{4}$ particles and PVP polymer according to the analysis of TGA and FT-IR experiments. The nanofiber membrane also exhibits good ferromagnetic and magnetic field responsive properties. The magnetic nanofibers have potential in biomedical applications.

Acknowledgments: This research is financially supported by the National Natural Science Foundation of China (project No. 51575543), the Natural Science Foundation of Guangdong Province, China (project No. 2014A030313211), and the Guangdong-Hongkong Technology Cooperation Funding Scheme (2016A050503027).

Author Contributions: Weilong Huang proposed the fabrication method and wrote the manuscript; Bin Liu performed the experiments and analyzed the data; Weilong Huang and Bin Liu contributed equally; Zhipeng Chen performed the finite element analysis; and Hongjian Wang, Lei Ren, Jiaming Jiao, Lin Zhuang, and Jie Luo contributed reagents, materials, and data analysis. Lelun Jiang managed the research and revised the manuscript.

Conflicts of Interest: The authors declare no conflict of interest.

\section{References}

1. Niu, S.; Zhang, L.; Wang, N.; Zhu, J.; Zhang, W.; Cheng, Z.; Zhu, X. Fabrication of magnetic nanofibers via surface-initiated raft polymerization and coaxial electrospinning. React. Funct. Polym. 2013, 73, 1447-1454. [CrossRef] 
2. Aguilar, L.E.; GhavamiNejad, A.; Park, C.H.; Kim, C.S. On-demand drug release and hyperthermia therapy applications of thermoresponsive poly-(NIPAAm-co-HMAAm)/ polyurethane core-shell nanofiber mat on non-vascular nitinol stents. Nanomed. Nanotechnol. Biol. Med. 2017, 13, 527-538. [CrossRef] [PubMed]

3. Cojocaru, C.; Dorneanu, P.P.; Airinei, A.; Olaru, N.; Samoila, P.; Rotaru, A. Design and evaluation of electrospun polysulfone fibers and polysulfone $/ \mathrm{NiFe}_{2} \mathrm{O}_{4}$ nanostructured composite as sorbents for oil spill cleanup. J. Taiwan Inst. Chem. E 2017, 70, 267-281. [CrossRef]

4. Song, H.-h.; Gong, X.; Williams, G.R.; Quan, J.; Nie, H.-1.; Zhu, L.-m.; Nan, E.-1.; Shao, M. Self-assembled magnetic liposomes from electrospun fibers. Mater. Res. Bull. 2014, 53, 280-289. [CrossRef]

5. Zhang, H.; Xia, J.Y.; Pang, X.L.; Zhao, M.; Wang, B.Q.; Yang, L.L.; Wan, H.S.; Wu, J.B.; Fu, S.Z. Magnetic nanoparticle-loaded electrospun polymeric nanofibers for tissue engineering. Mater. Sci. Eng. C-Mater. Biol. Appl. 2017, 73, 537-543. [CrossRef] [PubMed]

6. Zhao, F.; Wang, J.J.; Xu, B.C.; Liu, J.W.; Gao, H.T. Electrospinning fabrication and microwave absorption properties of lithium zinc ferrite micro/nanofibers. Chem. J. Chin. Univ.-Chin. 2017, 38, 922-928.

7. Guo, D.; Sun, Z.; Xu, L.; Gao, Y.; Dai, M.; Wang, S.; Chang, Q.; Wang, C.; Ma, D. Water-soluble luminescent-electrical-magnetic trifunctional composite nanofibers prepared via electrospinning technique. Mater. Lett. 2015, 159, 159-162. [CrossRef]

8. Bayat, M.; Yang, H.; Ko, F.K.; Michelson, D.; Mei, A. Electromagnetic interference shielding effectiveness of hybrid multifunctional $\mathrm{Fe}_{3} \mathrm{O}_{4}$ / carbon nanofiber composite. Polymer 2014, 55, 936-943. [CrossRef]

9. Kinsella, J.M.; Ivanisevic, A. DNA-templated magnetic nanowires with different compositions: Fabrication and analysis. Langmuir ACS J. Surf. Colloids 2007, 23, 3886-3890. [CrossRef] [PubMed]

10. Wang, H.; Chen, Q.W.; Sun, L.X.; Qi, H.P.; Yang, X.; Zhou, S.; Xiong, J. Magnetic-field-induced formation of one-dimensional magnetite nanochains. Langmuir 2009, 25, 7135-7139. [CrossRef] [PubMed]

11. He, K.; Xu, C.Y.; Zhen, L.; Shao, W.Z. Hydrothermal synthesis and characterization of single-crystalline $\mathrm{Fe}_{3} \mathrm{O}_{4}$ nanowires with high aspect ratio and uniformity. Mater. Lett. 2007, 61, 3159-3162. [CrossRef]

12. Martin, J.I.; Nogues, J.; Liu, K.; Vicent, J.L.; Schuller, I.K. Ordered magnetic nanostructures. Fabrication and properties. J. Magn. Magn. Mater. 2003, 256, 449-501. [CrossRef]

13. Gu, Q.; Cheng, C.; Gonela, R.; Suryanarayanan, S.; Anabathula, S.; Dai, K.; Haynie, D.T. DNA nanowire fabrication. Nanotechnology 2006, 17, 14. [CrossRef]

14. Nakhowong, R.; Chueachot, R. Synthesis and magnetic properties of copper cobaltite $\left(\mathrm{CuCo}_{2} \mathrm{O}_{4}\right)$ fibers by electrospinning. J. Alloys Compd. 2017, 715, 390-396. [CrossRef]

15. Wang, S.; Sun, Z.; Yan, E.; Yuan, J.; Gao, Y.; Bai, Y.; Chen, Y.; Wang, C.; Zheng, Y.; Jing, T. Magnetic composite nanofibers fabricated by electrospinning of $\mathrm{Fe}_{3} \mathrm{O}_{4}$ /gelatin aqueous solutions. Mater. Sci. Eng. B-Adv. Funct. Solid-State Mater. 2014, 190, 126-132. [CrossRef]

16. Huang, W.L.; Jiang, L.L.; Luo, J.; Chen, Z.P.; Ren, L.; Li, C.Y. Effect of magnetic field on stability of jet motion in electrospinning. Mater. Manuf. Process. 2016, 31, 1603-1607. [CrossRef]

17. Tian, L.; Zhao, C.; Li, J.; Pan, Z. Multi-needle, electrospun, nanofiber filaments: Effects of the needle arrangement on the nanofiber alignment degree and electrostatic field distribution. Text. Res. J. 2015, 85, 621-631. [CrossRef]

18. Liu, Z.; Ang, K.K.J.; He, J.H. Needle-disk electrospinning inspired by natural point discharge. J. Mater. Sci. 2017, 52, 1823-1830. [CrossRef]

19. Li, D.; Chen, W.; Sun, B.; Li, H.; Tong, W.; Ke, Q.; Chen, H.; Ei-Hamshary, H.; Al-Deyab, S.S.; Mo, X. A comparison of nanoscale and multiscale PCL/gelatin scaffolds prepared by disc-electrospinning. Colloids Surf. B Biointerfaces 2016, 146, 632-641. [CrossRef] [PubMed]

20. Fuh, Y.K.; Lien, L.C.; Chen, S.Y. High-throughput production of nanofibrous mats via a porous materials electrospinning process. J. Macromol. Sci. Part. B-Phys. 2012, 51, 1742-1749. [CrossRef]

21. Bhattacharyya, I.; Molaro, M.C.; Braatz, R.D.; Rutledge, G.C. Free surface electrospinning of aqueous polymer solutions from a wire electrode. Chem. Eng. J. 2016, 289, 203-211. [CrossRef]

22. Hsieh, C.T.; Lou, C.W.; Pan, Y.J.; Huang, C.L.; Lin, J.H.; Lin, Z.I.; Chen, Y.S.; Chiang, K.C. Fabrication of poly(vinyl alcohol) nanofibers by wire electrode-incorporated electrospinning. Fibers Polym. 2016, 17, 1217-1226. [CrossRef]

23. Zhao, C.C.; Lu, Y.; Pan, Z.J. Adhesion and protective properties of electrospun PVA/ES composites obtained by using spiral disk spinnerets. Text. Res. J. 2017, 87, 1685-1695. [CrossRef] 
24. Ali, U.; Niu, H.T.; Aslam, S.; Jabbar, A.; Rajput, A.W.; Lin, T. Needleless electrospinning using sprocket wheel disk spinneret. J. Mater. Sci. 2017, 52, 7567-7577. [CrossRef]

25. Yan, G.L.; Niu, H.T.; Shao, H.; Zhao, X.T.; Zhou, H.; Lin, T. Curved convex slot: An effective needleless electrospinning spinneret. J. Mater. Sci. 2017, 52, 11749-11758. [CrossRef]

26. Niu, H.T.; Lin, T.; Wang, X.G. Needleless electrospinning. I. A comparison of cylinder and disk nozzles. J. Appl. Polym. Sci. 2009, 114, 3524-3530. [CrossRef]

27. Vadodaria, K.; Stylios, G. A study of bubble electrospinning of ethylcellulose ultrafine fibres. Polym. Polym. Compos. 2016, 24, 265-272.

28. Chen, Y.J.; Dai, H.C.; Wang, W.; Qiang, W. Needleless electrospinning method based on tip effect of conductor. Chem. J. Chin. Univ.-Chin. 2017, 38, 975-981.

29. King, L.B.; Meyer, E.; Hopkins, M.A.; Hawkett, B.S.; Jain, N. Self-assembling array of magnetoelectrostatic jets from the surface of a superparamagnetic ionic liquid. Langmuir 2014, 30, 14143-14150. [CrossRef] [PubMed]

30. Yarin, A.L.; Zussman, E. Upward needleless electrospinning of multiple nanofibers. Polymer 2004, 45, 2977-2980. [CrossRef]

31. Irajizad, P.; Farokhnia, N.; Ghasemi, H. Dispensing nano-pico droplets of ferrofluids. Appl. Phys. Lett. 2015, 107, 191601. [CrossRef]

32. Timonen, J.V.I.; Latikka, M.; Leibler, L.; Ras, R.H.A.; Ikkala, O. Switchable static and dynamic self-assembly of magnetic droplets on superhydrophobic surfaces. Science 2013, 341, 253-257. [CrossRef] [PubMed]

33. Kujawska, A.; Knozowska, K.; Kujawa, J.; Kujawski, W. Influence of downstream pressure on pervaporation properties of PDMS and POMS based membranes. Sep. Purif. Technol. 2016, 159, 68-80. [CrossRef]

34. Rosensweig, R.E. Magnetic fluids. Ann. Rev. Fluid Mech. 1987, 19, 437-463. [CrossRef]

35. Wang, Z.; Liu, X.; Lv, M.; Chai, P.; Liu, Y.; Zhou, X.; Meng, J. Preparation of one-dimensional $\mathrm{CoFe}_{2} \mathrm{O}_{4}$ nanostructures and their magnetic properties. J. Phys. Chem. C 2008, 112, 15171-15175. [CrossRef]

36. Ponhan, W.; Maensiri, S. Fabrication and magnetic properties of electrospun copper ferrite $\left(\mathrm{CuFe}_{2} \mathrm{O}_{4}\right)$ nanofibers. Solid State Sci. 2009, 11, 479-484. [CrossRef]

37. Lubambo, A.F.; Ono, L.; Drago, V.; Mattoso, N.; Varalda, J.; Sierakowski, M.R.; Sakakibara, C.N.; Freitas, R.A.; Saul, C.K. Tuning $\mathrm{Fe}_{3} \mathrm{O}_{4}$ nanoparticle dispersion through PH in PVA/guar gum/electrospun membranes. Carbohyr. Polymer. 2015, 134, 775-783. [CrossRef] [PubMed]

38. Bayat, M.; Yang, H.; Ko, F. Electromagnetic properties of electrospun $\mathrm{Fe}_{3} \mathrm{O}_{4}$ / carbon composite nanofibers. Polymer 2011, 52, 1645-1653. [CrossRef]

39. Ho, C.H.; Tsai, C.P.; Chung, C.C.; Tsai, C.Y.; Chen, F.R.; Lin, H.J.; Lai, C.H. Shape-controlled growth and shape-dependent cation site occupancy of monodisperse $\mathrm{Fe}_{3} \mathrm{O}_{4}$ nanoparticles. Chem. Mater. 2011, 23, 1753-1760. [CrossRef]

(C) 2017 by the authors. Licensee MDPI, Basel, Switzerland. This article is an open access article distributed under the terms and conditions of the Creative Commons Attribution (CC BY) license (http://creativecommons.org/licenses/by/4.0/). 